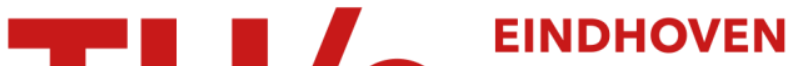 UNIVERSITY OF TECHNOLOGY
}

\section{Application of a dynamic vibration absorber to a piecewise linear beam system}

\section{Citation for published version (APA):}

Bonsel, J. H., Fey, R. H. B., \& Nijmeijer, H. (2004). Application of a dynamic vibration absorber to a piecewise linear beam system. Nonlinear Dynamics, 37(3), 227-243.

https://doi.org/10.1023/B:NODY.0000044646.70030.31

DOI:

10.1023/B:NODY.0000044646.70030.31

Document status and date:

Published: 01/01/2004

\section{Document Version:}

Publisher's PDF, also known as Version of Record (includes final page, issue and volume numbers)

\section{Please check the document version of this publication:}

- A submitted manuscript is the version of the article upon submission and before peer-review. There can be important differences between the submitted version and the official published version of record. People interested in the research are advised to contact the author for the final version of the publication, or visit the $\mathrm{DOI}$ to the publisher's website.

- The final author version and the galley proof are versions of the publication after peer review.

- The final published version features the final layout of the paper including the volume, issue and page numbers.

Link to publication

\section{General rights}

Copyright and moral rights for the publications made accessible in the public portal are retained by the authors and/or other copyright owners and it is a condition of accessing publications that users recognise and abide by the legal requirements associated with these rights.

- Users may download and print one copy of any publication from the public portal for the purpose of private study or research.

- You may not further distribute the material or use it for any profit-making activity or commercial gain

- You may freely distribute the URL identifying the publication in the public portal.

If the publication is distributed under the terms of Article $25 \mathrm{fa}$ of the Dutch Copyright Act, indicated by the "Taverne" license above, please follow below link for the End User Agreement:

www.tue.nl/taverne

Take down policy

If you believe that this document breaches copyright please contact us at:

openaccess@tue.nl

providing details and we will investigate your claim. 


\title{
Application of a Dynamic Vibration Absorber to a Piecewise Linear Beam System
}

\author{
J. H. BONSEL, R. H. B. FEY*, and H. NIJMEIJER \\ Department of Mechanical Engineering, Eindhoven University of Technology, P.O. Box 513, 5600 MB Eindhoven, \\ The Netherlands; *Author for correspondence (e-mail: R.H.B.Fey@tue.nl; fax: +31-40-2461418)
}

(Received: 7 October 2003; accepted: 9 June 2004)

\begin{abstract}
This paper deals with the application of a linear dynamic vibration absorber (DVA) to a piecewise linear beam system to suppress its first harmonic resonance. Both the undamped and the damped DVAs are considered. Results of experiments and simulations are presented and show good resemblance. It appears that the undamped DVA is able to suppress the harmonic resonance, while simultaneously many subharmonics appear. The damped DVA suppresses the first harmonic resonance as well as its super- and subharmonics.
\end{abstract}

Key words: absorber, beam, piecewise linear, vibration

\section{Introduction}

A dynamic vibration absorber (DVA) is a device consisting of an auxiliary mass-spring system which tends to neutralise the vibration of a structure to which it is attached. The application of a DVA to linear systems has been investigated by many authors, for example, Den Hartog [1], Hunt [2], and Korenev and Reznikov [3].

In this paper a DVA will be applied to a piecewise linear beam system in order to reduce the vibration of this system. This piecewise linear beam system consists of a pinned-pinned beam supported in the middle by a one-sided spring. In the past, several authors studied piecewise linear systems. Shaw and Holmes [4], Thompson et al. [5], and Natsiavas [6] have studied single degree of freedom systems, whereas Fey [7] and Van de Vorst [8] have investigated multi degree of freedom systems. Pun and Liu [9] have used a piecewise linear vibration absorber on a single degree of freedom linear system.

The piecewise linear beam system which is investigated in this paper is an archetype system. Many mechanical systems in engineering practice show similar dynamic behaviour. A practical example of a piecewise linear system is a system of solar array panels, which take care of the energy supply for satellites [10]. During launch the solar array panels are attached to the satellite in folded position and suffer from intensive vibration. To prevent the panel ends striking each other rubber snubbers are mounted, which act as elastic stops. In order to justify linear analysis to predict the dynamic behaviour of the structure, the snubbers are brought under pre-stress. As a negative consequence, the residual strength of the structure is low. An alternative is to lower the pre-stress, resulting in the snubbers loosing contact with the solar arrays. In that case, behaviour similar to the behaviour of a piecewise linear beam system can be seen.

Structures such as the one mentioned above, could benefit from the application of a DVA if vibration amplitudes can be reduced. The goal of this paper is therefore to investigate the possibility of reducing the vibrations of an archetype piecewise linear beam system using a linear DVA. Both simulations and 
experiments will be carried out using two types of DVAs: namely, the undamped DVA and the damped DVA.

In Section 2 the experimental set-up and its mathematical model will be described. The system without the one-sided spring will be modelled using the finite element method in combination with a dynamic reduction method. After coupling of the one-sided spring to the reduced model the dynamic behaviour of this piecewise linear beam system will be discussed briefly in Section 3. In Section 4 a brief overview of linear DVA theory will be given. The physical design of the DVA that is used in the piecewise linear beam system will be presented in Section 5. In Section 6 results of simulations and experiments will be shown and compared in which both the damped and the undamped DVA are applied to the piecewise linear beam system. Finally some conclusions and recommendations for future research will be given in Section 7.

\section{Experimental Set-up and Mathematical Model}

Figure 1 shows a drawing of the experimental set-up, including its material and geometrical properties. A steel beam with uniform cross section is supported by two leaf springs. In the middle of the beam a second beam is placed which is clamped at both ends. When the middle of the main beam has a negative deflection, the pin will be in contact with the main beam, resulting in a one-sided spring force.

The middle of the beam is harmonically excited in transversal direction by a rotating mass-unbalance that is driven by an electric motor. The mass-unbalance is coupled to the motor by a shaft with flexible couplings. The motor is able to rotate at constant rotational speeds up to 60 revolutions per second, resulting in sinusoidal excitation signals in the frequency range up to $60 \mathrm{~Hz}$.

The experimental set-up without the one-sided stiffness is modelled using a 111 degree of freedom (DOF) finite element model. If the number of DOFs is doubled, the first 10 eigenfrequencies change by less than $0.05 \%$. Therefore, the 111-DOF model can be considered accurate. The four lowest eigenfrequencies and eigenmodes of this model are shown in Figure 2. In order to reduce the number of DOFs, the dynamic reduction method of Rubin is applied [11]. This method is based on residual flexibility modes and free-interface eigenmodes up to a certain cut-off frequency. For linear analysis the reduced model is assumed to be accurate up to this cut-off frequency. The residual flexibility modes guarantee unaffected (quasi-)static behaviour.

It is assumed that the damping in the experimental set-up without the one-sided spring can be modelled as modal damping. The modal damping coefficient of the first mode is determined experimentally and turns out to be 0.02 . This same amount of damping is assumed for all other modes.

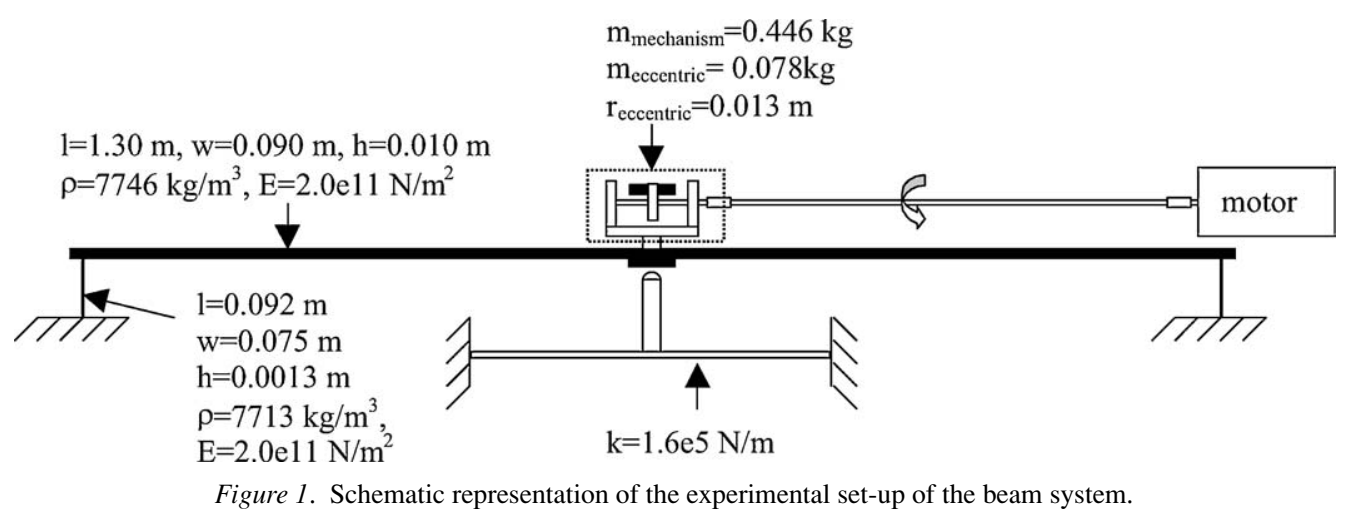




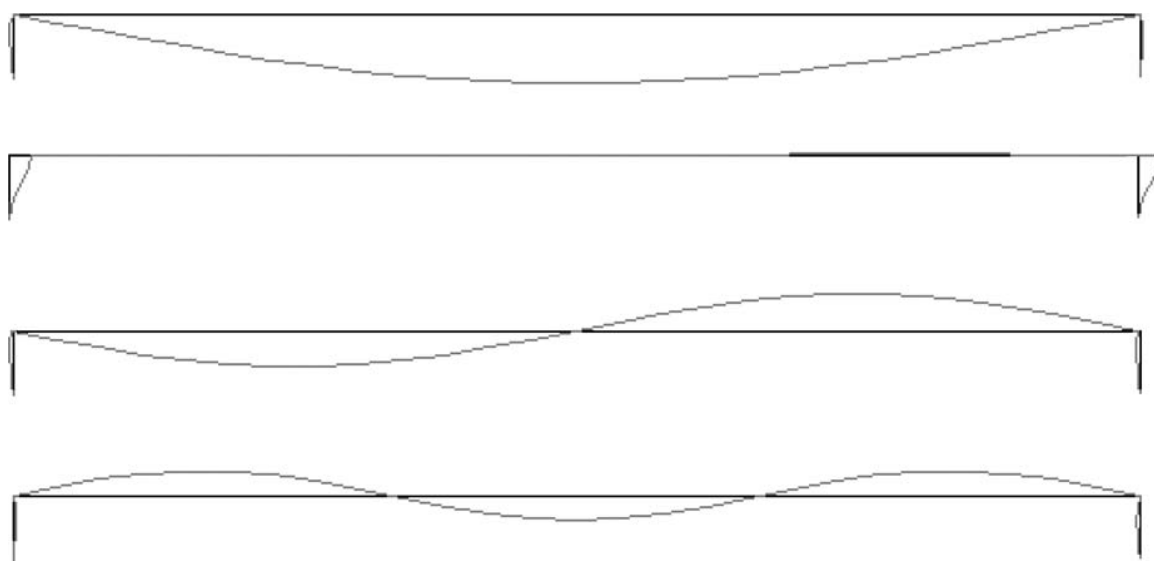

Figure 2. First four eigenmodes of the beam system without the one-sided stiffness.

The beam that acts as one-sided stiffness, is modelled as a massless spring. This can be justified by the fact that the first resonance of this beam occurs at $170 \mathrm{~Hz}$, which is far outside the frequency range of interest. Using this one-sided stiffness, a ratio $\alpha$ can be defined which is the ratio of the one-sided stiffness and the stiffness associated with the first eigenmode of the main beam. This ratio is sometimes used to express the amount of nonlinearity of the system. In this case $\alpha$ is equal to 4.6 , which means that the amount of nonlinearity is moderate.

Earlier research [8] showed that a reduced model of this piecewise linear beam system containing only the first free-interface eigenmode shows almost the same behaviour in the frequency range of interest as a model in which higher free-interface eigenmodes are taken into account as well. Therefore, a 2-DOF model consisting of the first free-interface eigenmode and one residual flexibility mode is used to calculate the dynamic response of the system. The residual flexibility mode is defined for the transversal displacement of the middle of the beam where the excitation force is applied and where the beam is coupled to the one-sided spring.

The equations of motion of the reduced model are:

$$
\begin{aligned}
M_{\text {red }} \ddot{p}(t)+B_{\text {red }} \dot{p}(t)+K_{\text {total }} p(t) & =f_{\text {red }}(t) \\
K_{\text {total }} & = \begin{cases}K_{\text {red }} & \text { if } q_{\text {mid }}>0 \\
K_{\text {red }}+K_{\mathrm{nl}} & \text { if } q_{\text {mid }} \leq 0\end{cases}
\end{aligned}
$$

In this equation the matrices $M_{\text {red }}, B_{\text {red }}$ and $K_{\text {red }}$ are the reduced mass, damping and stiffness matrices. $K_{\mathrm{nl}}$ is the matrix including only the stiffness of the one-sided spring. $q_{\mathrm{mid}}$ is the DOF corresponding to the transversal displacement of the middle of the beam. The vector $p$ is defined as:

$$
p=\left[\begin{array}{c}
q_{\text {mid }} \\
p_{1}
\end{array}\right]
$$

In this vector $p_{1}$ is a generalised DOF corresponding to the first free-interface eigenmode of the linear beam system. 
230 J. H. Bonsel et al.

\section{Periodic Solutions}

Periodic solutions of the 2-DOF model including the one-sided stiffness are calculated using the finite difference method in combination with path following techniques. The local stability of the solutions is determined using Floquet theory. Calculations are carried out for excitation frequencies in the range from 5 to $60 \mathrm{~Hz}$. For each excitation frequency the maximum transversal displacement of the middle of the beam $q_{\text {mid,max }}$ is stored, which is defined as:

$$
q_{\text {mid,max }}=\max \left(q(t)_{\text {mid }}\right)-\min \left(q(t)_{\text {mid }}\right)
$$

in which $q(t)_{\text {mid }}$ is the periodic displacement signal of the middle of the beam.

In order to verify the calculations, experiments are carried out on the experimental set-up of the piecewise linear beam system. In these experiments the middle of the beam is excited by the rotating mass unbalance at a constant frequency and the resulting transversal acceleration of the middle of the beam is measured by an accelerometer, which is attached to the beam. This is done for a large number of frequencies throughout the frequency range of interest. To obtain displacement signals the measured acceleration signals are integrated twice. Subsequently, the maximum displacements at each frequency are determined according to (3). In order to be able to compare these displacements with the theoretical results, they are divided by the amplitude of the force that excites the system. In general a nonlinear system cannot be scaled in this way, but it can be seen from (1) that this is permitted in this case because the beam and one-sided spring are flush.

Figure 3 shows both the experimentally obtained and the calculated maximum transversal displacements divided by the excitation force amplitude for the excitation frequency range of 5-60 Hz. The calculated responses are shown as solid lines (stable response) and dotted lines (unstable response), whereas the various markers correspond to the measured responses. The figure shows that the experimental

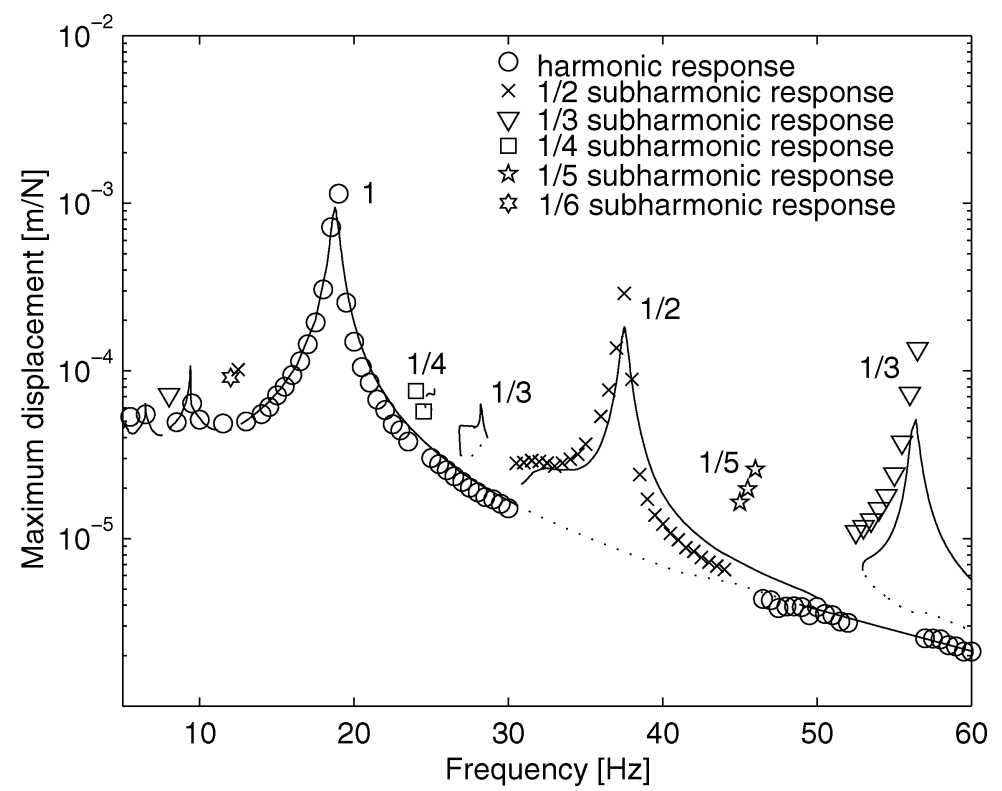

Figure 3. Maximum transversal displacement of the middle of the beam divided by the excitation force amplitude for excitation frequencies in the range $5-60 \mathrm{~Hz}$. 
results agree quite well with the calculated results: the frequencies at which the resonances occur agree very accurately, but the heights of some peaks deviate.

In the figure, a harmonic resonance occurs at $19 \mathrm{~Hz}$. At around 38 and $57 \mathrm{~Hz}$ a $1 / 2$ and $1 / 3$ subharmonic resonance can be seen, which are both related to this harmonic resonance at $19 \mathrm{~Hz}$. Furthermore, a second and third superharmonic resonance can be seen near 9.5 and $6.5 \mathrm{~Hz}$, respectively, which are also related to the harmonic resonance at $19 \mathrm{~Hz}$. As a result of the superharmonic resonance at $9.5 \mathrm{~Hz}$, a $1 / 3$ and $1 / 5$ subharmonic resonance peak occur near 28 and $46 \mathrm{~Hz}$, respectively. In addition, a 1/4 subharmonic resonance peak occurs near $26 \mathrm{~Hz}$, which is related to the superharmonic resonance at $6.5 \mathrm{~Hz}$.

\section{Linear DVA Theory}

Figure 4 shows a schematic representation of a DVA (mass $m_{2}$, stiffness $k_{2}$, damping $c$ ) attached to a vibrating single DOF system (mass $m_{1}$, stiffness $k_{1}$ ). In this section the two main types of DVAs will be discussed very briefly; namely, the undamped DVA $(c=0)$ and damped DVA $(c>0)$. For more information on DVA theory, the reader is referred to Den Hartog [1], Hunt [2], and Korenev and Reznikov [3].

\subsection{THE UNDAMPED DVA}

In the case of an undamped DVA the natural frequency of the DVA is chosen equal to the frequency of the periodically varying force (i.e. $\omega_{2}=\sqrt{k_{2} / m_{2}}=\omega$ ). In this way the main mass $m_{1}$ will not vibrate at all. The undamped DVA is most effective if it is used to reduce the vibration of the main system when it is at resonance. In that case the natural frequency of the DVA is equal to the resonance frequency of the main system, i.e. $\omega_{1}=\omega_{2}$.

For this specific case calculations have been carried out and the amplitudes $a_{1}$ and $a_{2}$ of the main mass $m_{1}$ and the DVA mass $m_{2}$, respectively, are plotted as a function of the forcing frequency ratio $\omega / \omega_{1}$ in Figure 5. In the diagrams, the amplitudes are scaled with the static deflection $x_{\mathrm{st}}$, which is the deflection that occurs under static load. The diagrams are obtained using a DVA mass $m_{2}$ which is $1 / 10$ of the main mass $m_{1}$.

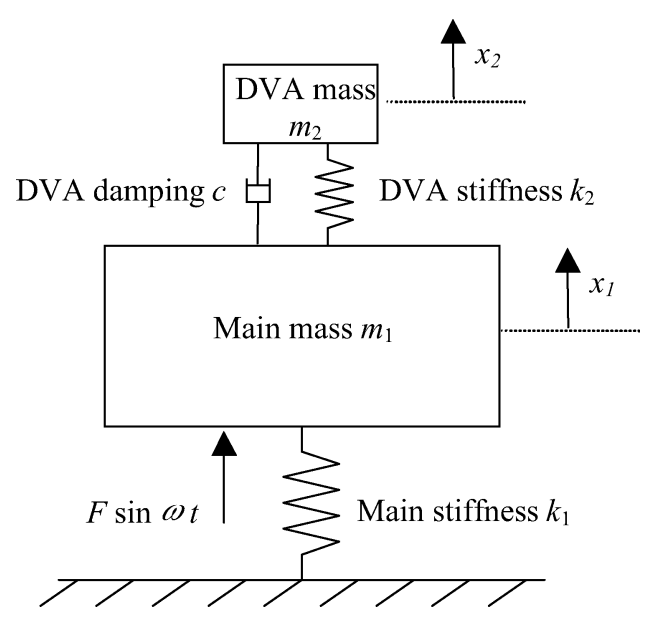

Figure 4. Schematic representation of a DVA attached to a single DOF vibrating system. 

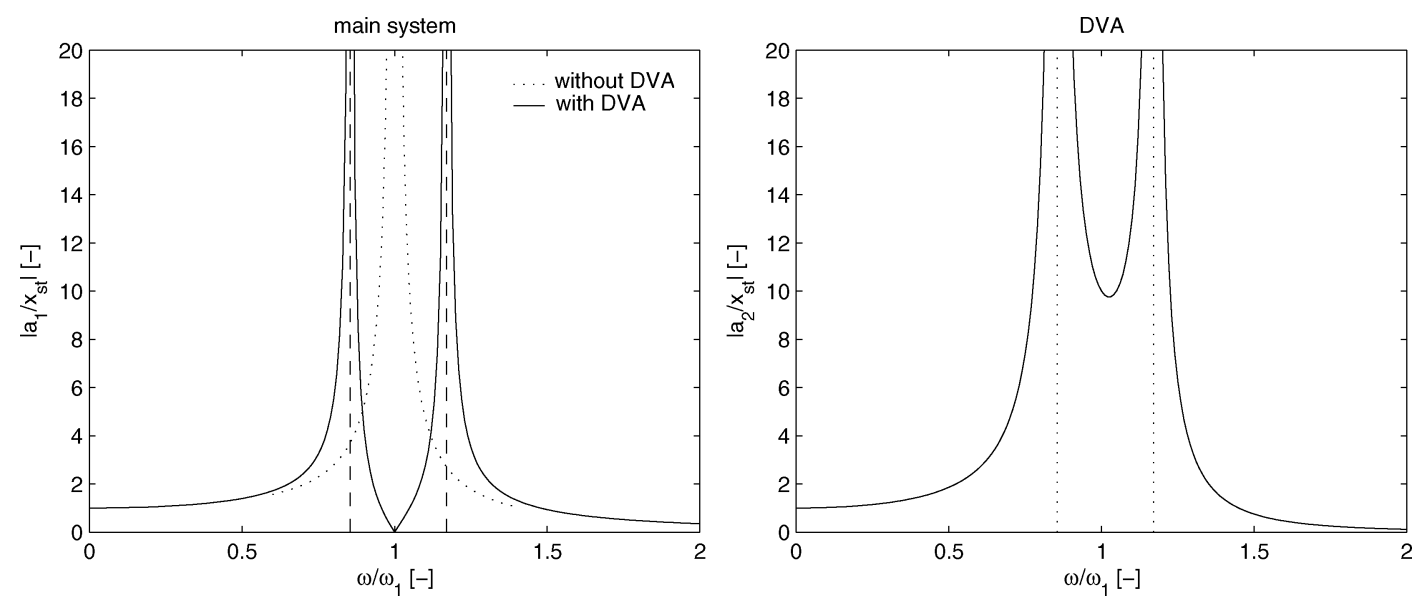

Figure 5. Amplitudes of main system (left) and DVA (right) as a function of the forcing frequency ratio. The DVA mass is one-tenth of the main system mass.

It can be seen that at the original resonance frequency $\frac{\omega^{2}}{\omega_{1}^{2}}=1$, the amplitude of the main system $a_{1}$ is now zero. Furthermore, two new resonance frequencies arise at the left and the right of the original resonance frequency. These resonance frequencies become further apart if the DVA mass is chosen larger.

\subsection{THE DAMPED DVA}

By adding damping to the DVA $(c>0)$, the frequency range over which the response amplitude is reduced can considerably be increased. In Den Hartog [1] expressions are derived in order to obtain the damping $c$ and stiffness $k_{2}$ of the DVA, given a value of the DVA mass $m_{2}$, that result in a minimum dynamic response, i.e. a response for which the peaks are minimal:

$$
\begin{aligned}
f & =\frac{1}{1+\mu} \\
\frac{c}{C} & =\sqrt{\frac{3 \mu}{8(1+\mu)^{3}}}
\end{aligned}
$$

where

$$
\begin{aligned}
& \mu=m_{2} / m_{1}, \\
& f=\omega_{2} / \omega_{1}, \\
& C=2 m_{2} \omega_{1} .
\end{aligned}
$$

Figure 6 shows the amplitude of the main mass $m_{1}$ as a function of the forcing frequency ratio using the optimum stiffness and optimum damping and a DVA mass $m_{2}$ which is one-twentieth of the main mass $m_{1}$. It can be seen that the frequency response is flattened using this damped DVA and that no high resonance peaks occur throughout the frequency range. 


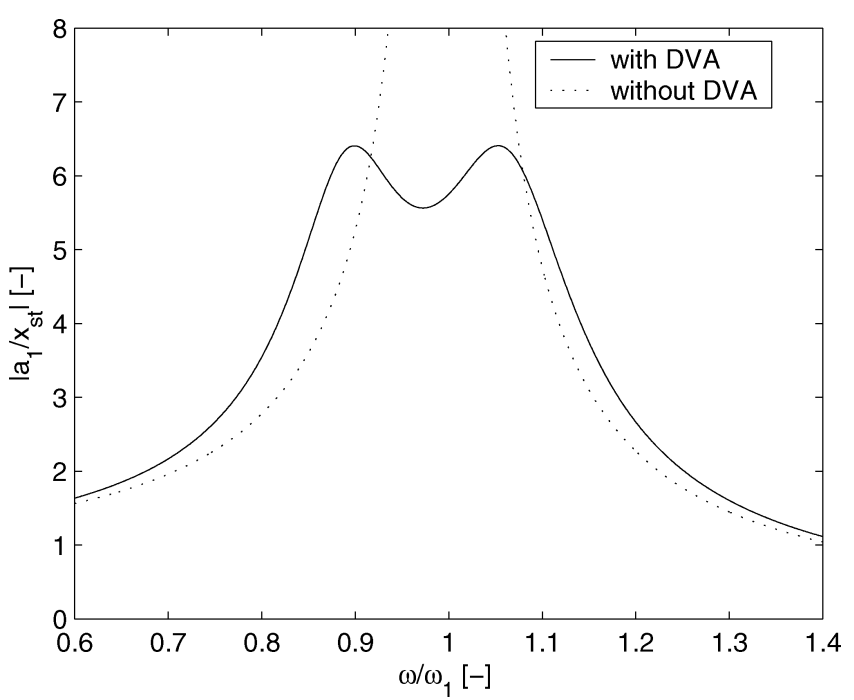

Figure 6. Amplitude ratio of the main system as a function of the forcing frequency ratio using a DVA with optimum stiffness and damping.

\section{DVA Design}

In order to apply a DVA to the experimental set-up of the beam system, a DVA is designed and manufactured. A schematic representation of the design is shown in Figure 7 and a picture of the manufactured DVA is shown in Figure 8. It consists of two cantilever beams with additional masses of $0.5 \mathrm{~kg}$ at the ends, which leads to a total DVA mass $m_{2}$ of $1 \mathrm{~kg}$. By moving a mass along its cantilever beam, the stiffness can be tuned very precisely and consequently its natural frequency as well. The reason for using two cantilever beams instead of one is symmetry. Due to the presence of the excitation mechanism and the one-sided spring construction it is not possible to attach the DVA in the most favourable position for suppressing the first harmonic resonance: the middle of the beam. Furthermore, due to the limited space available, it is not possible to turn the DVA 90 degrees so that it would be perpendicular to the main beam.

To verify whether the designed DVA really acts like a single DOF mass-spring system, some simulations are carried out. These simulations confirm that the dynamic behaviour of the designed DVA is almost equal to the dynamic behaviour of a single DOF mass-spring system.

The damping of the manufactured DVA is determined by means of an experiment, which results in a modal damping coefficient of 0.004 . This damping coefficient is very low, so the DVA can be considered as an undamped DVA.

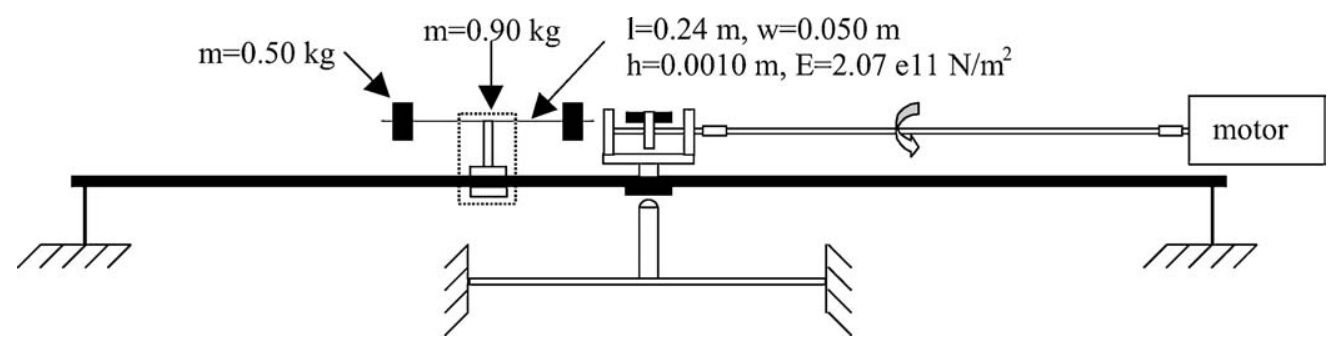

Figure 7. Schematic representation of the experimental set-up of the beam system including designed DVA. 


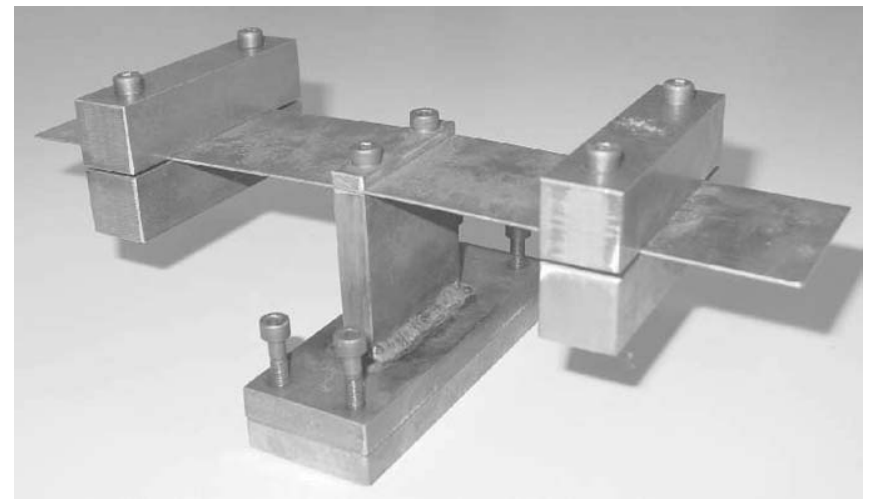

Figure 8. Picture of the manufactured DVA.

\section{Numerical and Experimental Results}

In this section the dynamics of the piecewise linear beam system including the DVA will be studied. Both experiments and simulations are carried out and the results will be compared. Two cases will be considered: namely, the case in which an undamped DVA is used and the case in which a damped DVA is used.

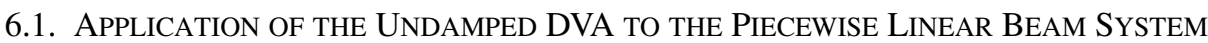

Simulations are carried out in which the undamped DVA, modelled as a point-mass and a spring, is attached to the beam $20 \mathrm{~cm}$ from the middle. Its eigenfrequency is tuned to the first harmonic resonance of the beam system, which is $19 \mathrm{~Hz}$.

Periodic solutions are calculated using a 6-DOF model, consisting of the first three free-interface eigenmodes of the linear beam system, two residual flexibility modes and one DOF that corresponds to the displacement of the DVA point-mass. The calculated responses are verified by means of experiments, in which the acceleration of the middle of the beam and of one of the DVA masses is measured. In contrast to the simulations in Section 3, the first three free-interface eigenmodes of the linear beam system are taken into account instead of only the first. This is done because the second and third eigenmode of the linear beam system (see Figure 2) are excited by the force of the DVA, whereas these are not excited in the case when only the shaker applies a force in the middle of the beam. One of the two residual flexibility modes is again defined for the transversal displacement of the middle of the beam where the one-sided spring is attached and where the excitation force is applied. The other residual flexibility mode is defined for the transversal displacement of the beam at the position where the DVA is attached.

In the case of the 6-DOF model the column $p$ in (1) is defined as:

$$
p=\left[\begin{array}{c}
q_{\mathrm{mid}} \\
q_{\mathrm{abs}} \\
p_{1} \\
p_{2} \\
p_{3} \\
q_{m_{2}}
\end{array}\right]
$$



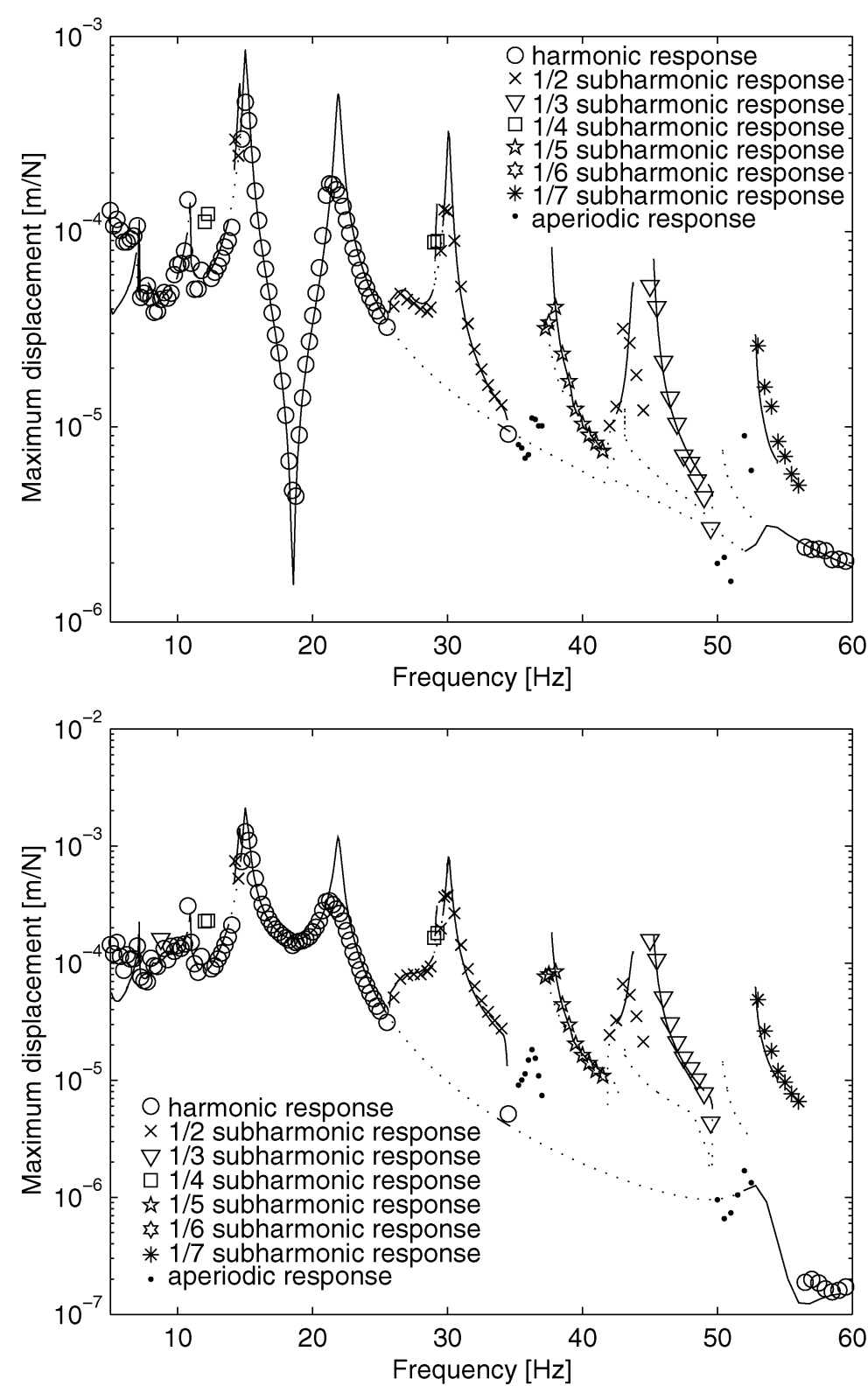

Figure 9. Maximum transversal displacement, divided by the excitation force amplitude, of the middle of the beam (on top) and DVA mass (on the bottom) for excitation frequencies in the range 5-60 Hz.

In this vector $p_{1}, p_{2}$ and $p_{3}$ are the generalised DOFs corresponding to the first three free-interface eigenmodes of the linear beam system. $q_{\mathrm{abs}}$ is the DOF corresponding to the transversal displacement of the beam at the point where the DVA is attached. $q_{m_{2}}$ is the DOF corresponding to the displacement of the DVA mass $m_{2}$ itself.

Figure 9 shows the experimental and the calculated maximum transversal displacements, divided by the excitation force amplitude, of the middle of the beam and the DVA mass for excitation frequencies in the range 5-60 Hz. The calculated responses are shown as solid lines (stable response) and dotted lines (unstable response), whereas the various markers correspond to the measured responses. 
In the upper diagram it can be seen that a stable harmonic anti-resonance occurs at approximately $19 \mathrm{~Hz}$, which is the frequency at which the original harmonic resonance occurs (see Figure 3) and which is also the eigenfrequency of the DVA. Also two new harmonic resonances occur at approximately 15 and $22 \mathrm{~Hz}$. Both these effects agree with the case of an undamped DVA applied to a linear mass-spring system (see Figure 5). This result can be explained by the fact that the undamped DVA generates a force that counteracts the excitation force. Therefore, also in this nonlinear case the resonance is suppressed. Note however that the response is small but not zero as in Figure 5, which is due to the fact that the DVA is not placed in the middle of the beam where the excitation takes place. In this way a moment acts on the beam, caused by the vertical forces of the DVA and the excitation.

In addition to these two new harmonic resonances many subharmonic resonances occur, which can be seen in both diagrams of Figure 9. At approximately 30 and $45 \mathrm{~Hz}$ a $1 / 2$ and $1 / 3$ subharmonic resonance occur, which are both related to the harmonic resonance near $15 \mathrm{~Hz}$. At approximately $44 \mathrm{~Hz}$, a 1/2 subharmonic resonance occurs, which is related to the harmonic resonance near $22 \mathrm{~Hz}$. Furthermore, a second and third superharmonic resonance occur near 11 and $7.3 \mathrm{~Hz}$, respectively, which are also related to the harmonic resonance near $22 \mathrm{~Hz}$. As a result of the superharmonic resonance near $7.3 \mathrm{~Hz}$, a 1/2,1/4,1/5 and 1/7 subharmonic resonance occur near 14.5, 29, 37 and $52 \mathrm{~Hz}$, respectively.

Both diagrams of Figure 9 show that the experimental results agree quite well with the numerically calculated results. The main differences that occur are the heights of the peaks. These differences are probably caused by the fact that the damping cannot accurately be modelled by modal damping.

The experimental and calculated results are also compared in the time domain. Figure 10 shows the experimental (dotted lines) and calculated (solid lines) time domain plots of the harmonic response at $20 \mathrm{~Hz}$, the $1 / 2$ subharmonic response at $27 \mathrm{~Hz}$ and the $1 / 3$ subharmonic response at $46 \mathrm{~Hz}$. The figures on the left show the time history of the transversal displacement of the middle of the beam; the figures on the right show the time history of the displacement of the DVA mass. It can be seen that the experimental responses agree quite well with the calculated responses in the time domain.

In the frequency ranges between 34.5 and $37 \mathrm{~Hz}$ and between 49.5 and $52 \mathrm{~Hz}$ periodic behaviour could not be found, neither in the experiments nor in the simulations. Numerical integration shows that in both frequency ranges a quasi-periodic $\rightarrow$ locked $\rightarrow$ chaotic sequence occurs [12-14]. The stable solutions just outside these ranges become unstable via secondary Hopf bifurcations.

Figure 11 shows four calculated Poincaré sections in the frequency range between 34.5 and $37 \mathrm{~Hz}$, which are obtained by means of numerical integration. Actually, the Poincare sections show a 2dimensional subspace of the 12-dimensional state space. Only the transversal displacement and velocity of the middle of the beam are depicted. The first Poincare section suggests quasi-periodic behaviour at $35 \mathrm{~Hz}$, however, this is not completely certain since this is only a 2-dimensional subspace of the 12dimensional state space. In order to be certain about the dynamical behaviour some additional research is necessary, for example the calculation of Lyapunov exponents [15] or inspection of the phase space by means of the Tisean package [16]. The Poincaré section at $35.4 \mathrm{~Hz}$ shows a $1 / 43$ subharmonic solution (frequency locking). Then at $35.41 \mathrm{~Hz}$ a weakly chaotic attractor can be seen. Finally at $35.6 \mathrm{~Hz}$ the attractor is fully chaotic.

Similar behaviour is found in the experiments. This is shown in Figure 12. The left Poincare section is obtained at an excitation frequency of $35.25 \mathrm{~Hz}$. The closed loop that is visible suggests quasi-periodic behaviour, however, due to the inaccuracies of the measurements it is uncertain whether this indeed is the case. The right Poincaré section of Figure 12 indicates the frequency locking phenomenon. In the experiments, no clear chaotic behaviour is found.

The above experimental and numerical results show that a stable harmonic anti-resonance occurs at the frequency of the original harmonic resonance. Moreover, no unstable harmonic solutions are found 

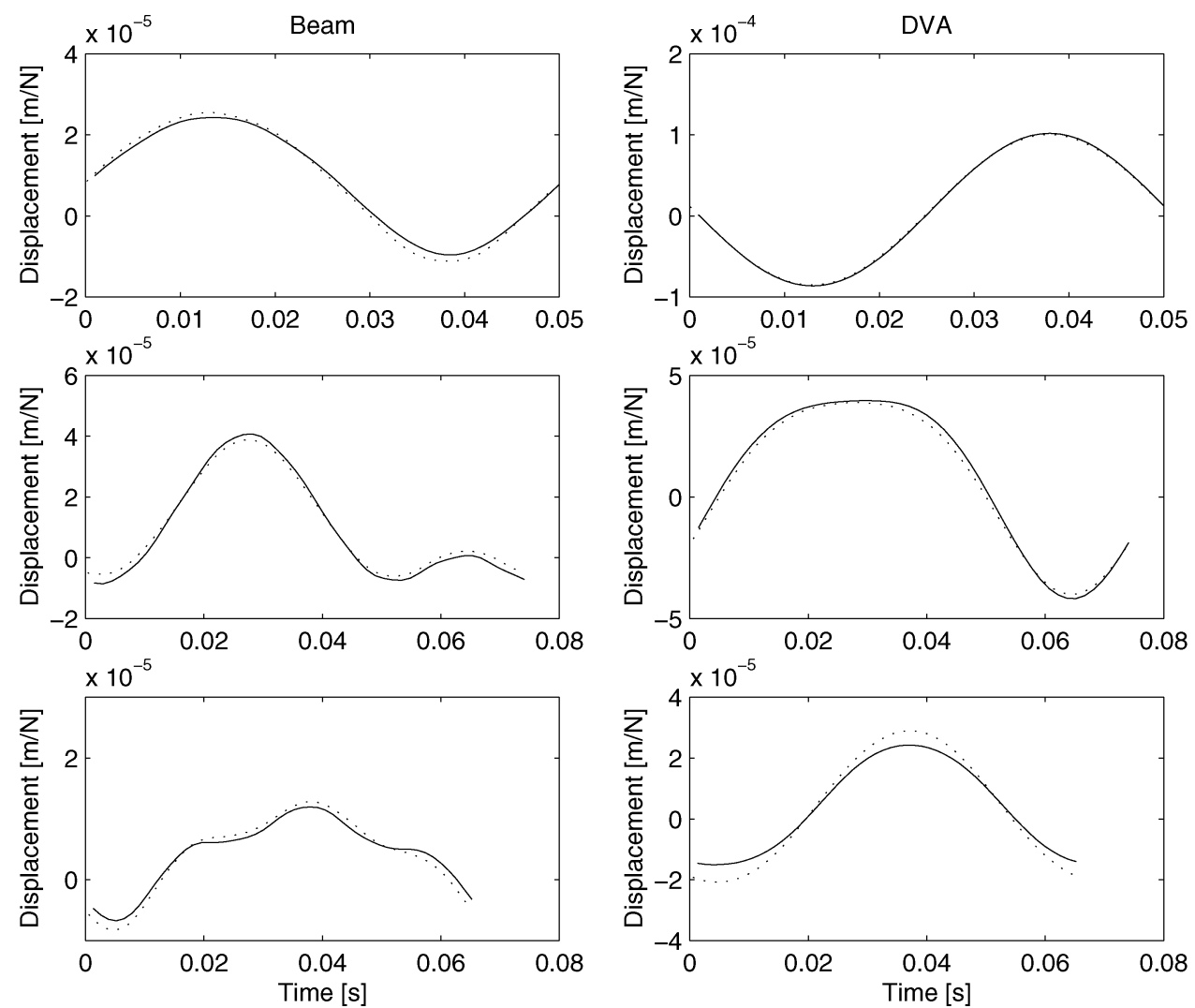

Figure 10. Time domain plots of the harmonic response at $20 \mathrm{~Hz}$ (top), the $1 / 2$ subharmonic response at $27 \mathrm{~Hz}$ (middle) and the $1 / 3$ subharmonic response at $46 \mathrm{~Hz}$ (bottom).

between the two new harmonic resonances at 15 and $22 \mathrm{~Hz}$. In order to investigate the robustness of the stability of the harmonic anti-resonance, some additional simulations are carried out for other values of the DVA mass. As stated earlier, a higher DVA mass leads to resonance peaks which lie further apart.

Figure 13 shows the calculated maximum transversal displacement of the middle of the beam divided by the excitation force amplitude using an undamped DVA, with a DVA mass of $4 \mathrm{~kg}$, which is again tuned to the first harmonic resonance at $19 \mathrm{~Hz}$. It should be noted that this value for the DVA mass is unrealistic for real applications, since the mass of the beam is $10 \mathrm{~kg}$, which means that the DVA mass would be $40 \%$ of the main mass. Using this DVA, the two new harmonic resonance peaks become further apart and appear at approximately 11.5 and $26 \mathrm{~Hz}$. Near the unstable harmonic resonance peak at $11.5 \mathrm{~Hz}$, a stable $1 / 2$ subharmonic resonance occurs and at $13.5 \mathrm{~Hz}$ a superharmonic resonance occurs. The $1 / 2$ subharmonic responses of these resonances result in a $1 / 4$ subharmonic resonance near $23 \mathrm{~Hz}$ and a $1 / 2$ subharmonic resonance near $27 \mathrm{~Hz}$. In addition, two unstable regions appear near 17 and $19 \mathrm{~Hz}$. Near $17 \mathrm{~Hz}$ a stable $1 / 2$ subharmonic solution is found whereas near $19 \mathrm{~Hz}$ no stable periodic solution is found. Here a quasi-periodic $\rightarrow$ locked $\rightarrow$ chaotic sequence occurs. Moreover, near $25 \mathrm{~Hz}$ the $1 / 2$ subharmonic response becomes unstable, resulting in quasi-periodic behaviour consisting of two closed loops in the Poincaré section, which is shown in Figure 14.

The above results show that some unstable regions occur between the two harmonic resonance peaks; however, the harmonic anti-resonance is still stable. Figure 15 again shows the calculated maximum transversal displacement of the middle of the beam divided by the excitation force amplitude using 

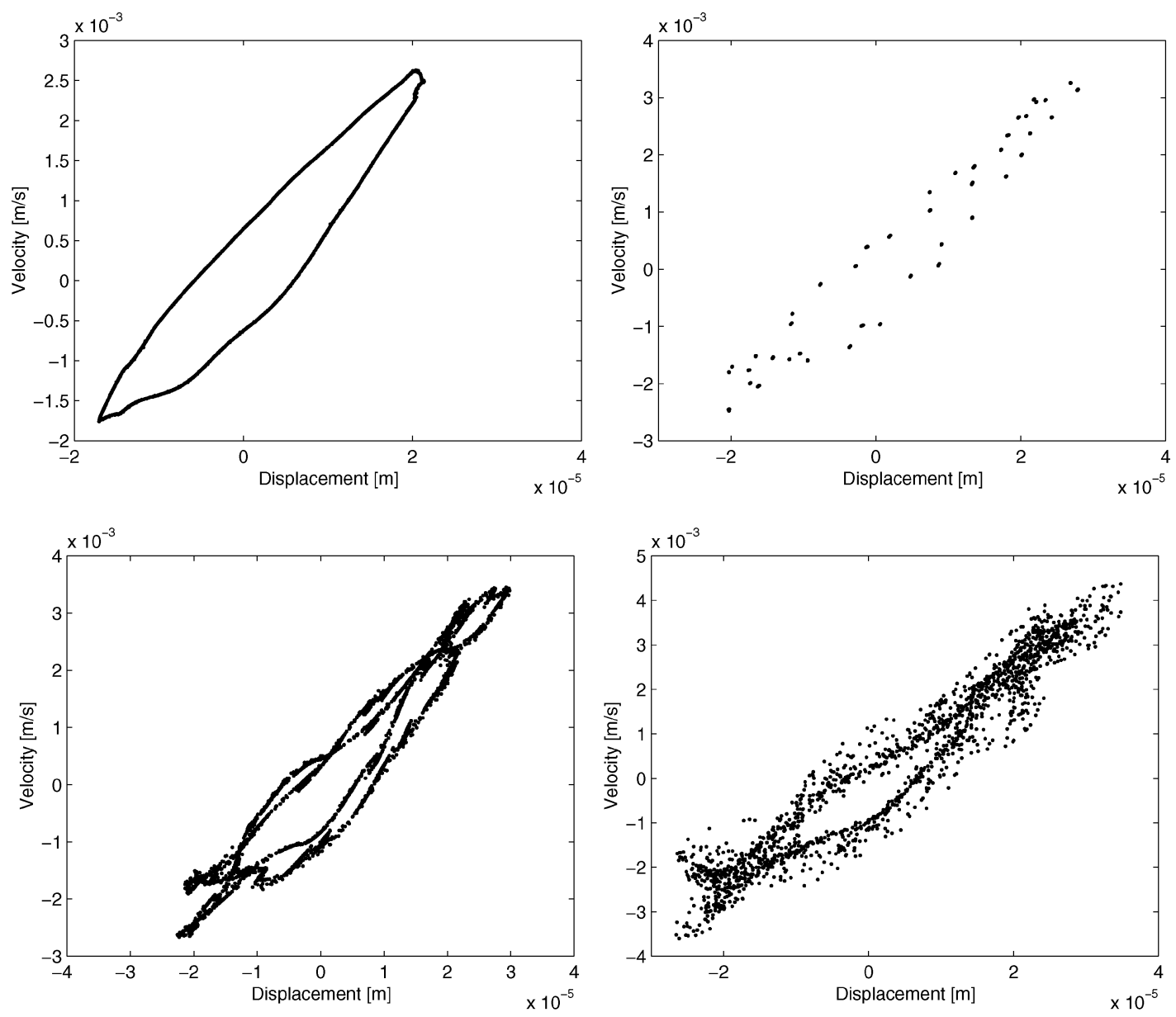

Figure 11. Calculated projected Poincaré sections at $35 \mathrm{~Hz}$ (upper left), $35.4 \mathrm{~Hz}$ (upper right), $35.41 \mathrm{~Hz}$ (lower left) and $35.6 \mathrm{~Hz}$ (lower right).
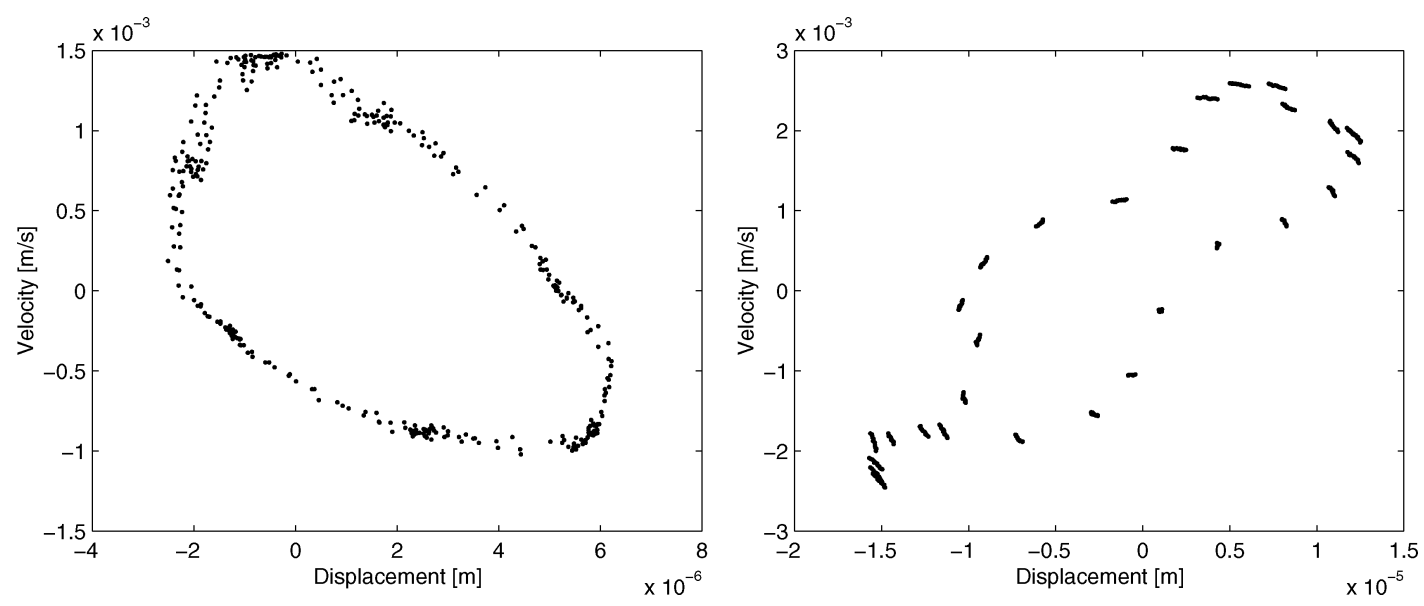

Figure 12. Measured projected Poincaré sections at $35.25 \mathrm{~Hz}$ (left) and $36.25 \mathrm{~Hz}$ (right). 


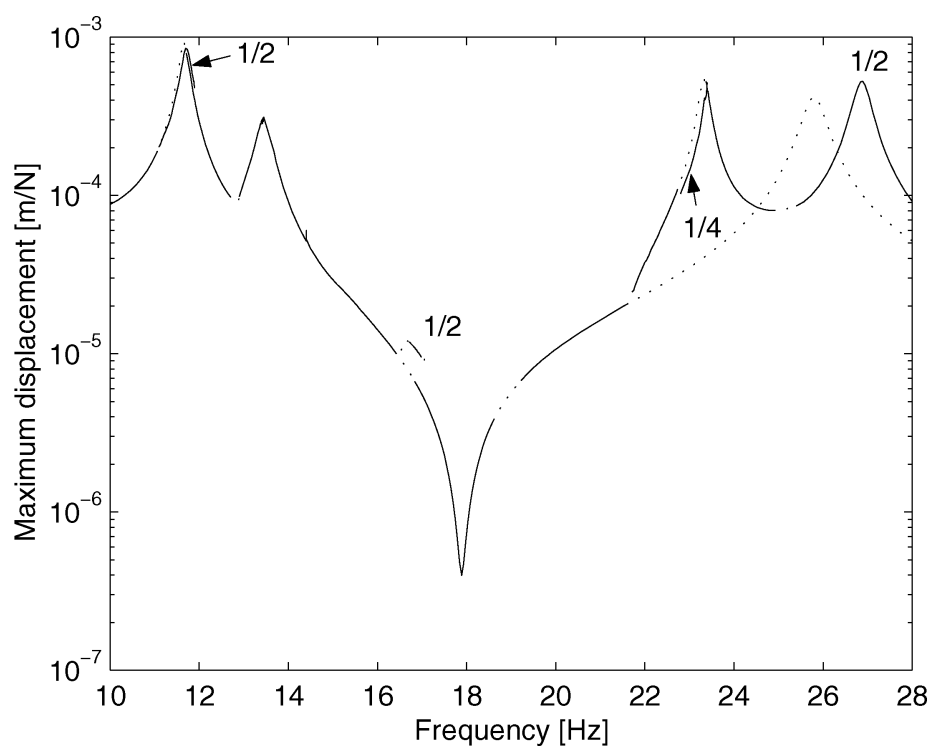

Figure 13. Calculated maximum transversal displacement of the middle of the beam divided by the excitation force amplitude for excitation frequencies in the range 10-28 Hz using a DVA mass of $4 \mathrm{~kg}$.

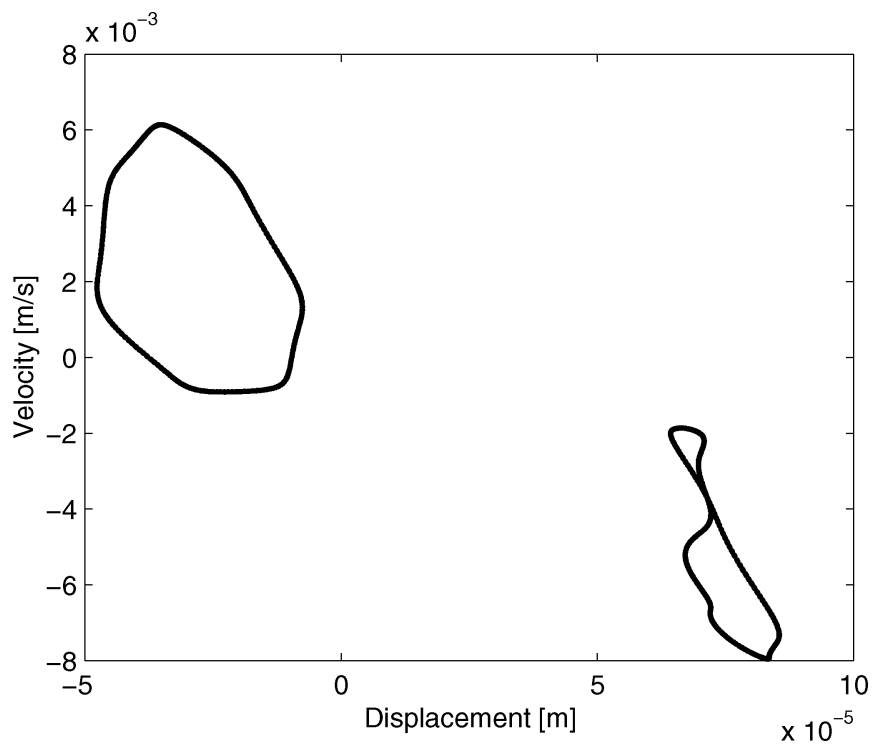

Figure 14. Calculated projected Poincaré section at $25.1 \mathrm{~Hz}$.

an undamped DVA. In this figure however, several curves are shown, each corresponding to a certain DVA mass. Although all DVAs are tuned to $19 \mathrm{~Hz}$, the various anti-resonances differ a little bit in frequency. This is caused by the fact that the DVA is not placed in the middle of the beam where the excitation takes place. The figure shows that for increasing DVA mass, the unstable region at the left of the anti-resonance comes closer to the anti-resonance. However, for a DVA mass larger than $5 \mathrm{~kg}$ it disappears. This suggests that the anti-resonance is indeed always stable. However, these results do not guarantee that no coexisting large amplitude response exists. 


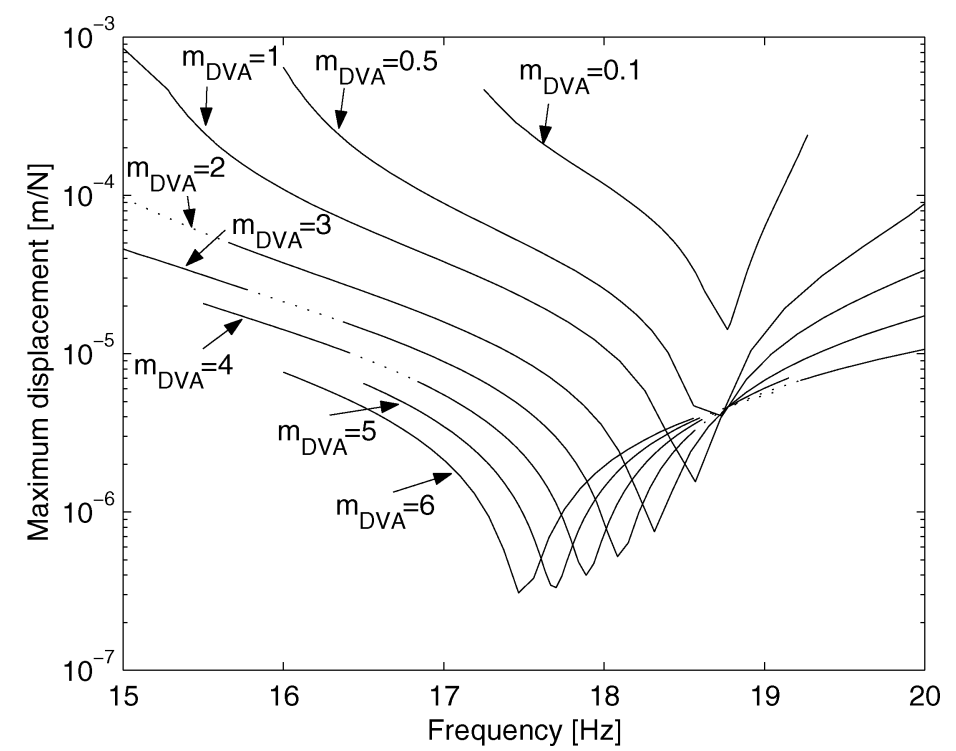

Figure 15. Calculated maximum transversal displacement of the middle of the beam divided by the excitation force amplitude for excitation frequencies in the range $15-20 \mathrm{~Hz}$ using various DVA masses.

\subsection{Application of the Damped DVA to the Piecewise Linear Beam System}

Simulations are carried out in which a damped DVA with DVA mass of $1 \mathrm{~kg}$, modelled as a point-mass supported by a spring and a damper, is attached to the beam $30 \mathrm{~cm}$ from the middle. The DVA damping and stiffness are tuned according to (4) and (5) to suppress the first harmonic resonance near $19 \mathrm{~Hz}$. The resulting numerical values are: $\mu=0.10, f=0.91$ and $c=38.2 \mathrm{Ns} / \mathrm{m}$. It should be noted that in the case of a multi DOF system, such as the beam system, $\mu$ is defined as the ratio between the DVA mass $m_{2}$ and the reduced mass of the multi DOF system corresponding to a particular mode and position. In this case it corresponds to the first eigenmode.

Figure 16 shows the calculated maximum transversal displacement of the middle of the beam divided by the excitation force amplitude with (grey lines) and without (black lines) the damped DVA attached. Again the solid lines correspond to stable solutions, whereas the dotted lines correspond to unstable solutions. It can be seen that the harmonic resonance near $19 \mathrm{~Hz}$ is suppressed in a way similar to the linear case (see Figure 6). In addition, the $1 / 2$ subharmonic resonance is suppressed. The $1 / 3$ subharmonic resonance near $57 \mathrm{~Hz}$ completely vanishes. This can be seen in more detail in Figure 17. This figure shows the 1/3 subharmonic resonance for the case without DVA and for several cases with a DVA attached which is optimally damped according to (5). The DVA stiffness however, is gradually increased to its optimum value $k_{\mathrm{opt}}\left(=m_{2} \omega_{2}^{2}\right)$, which results from (4) and (6). It can be seen that the frequency range in which the $1 / 3$ subharmonic resonance occurs, becomes smaller as the stiffness approaches its optimum value $k_{\mathrm{opt}}$. For $k=k_{\mathrm{opt}}$ the $1 / 3$ subharmonic response has completely disappeared. The fact that the damped DVA not only suppresses the harmonic resonance but also its corresponding super- and subharmonic resonances, can be attributed to the nonlinear couplings between the harmonic resonance and the super- and subharmonic resonances.

To verify the simulations, experiments are performed in which the DVA is damped by two air dampers attached at the ends of the steel plate of the DVA. The other ends of the air dampers are connected to 


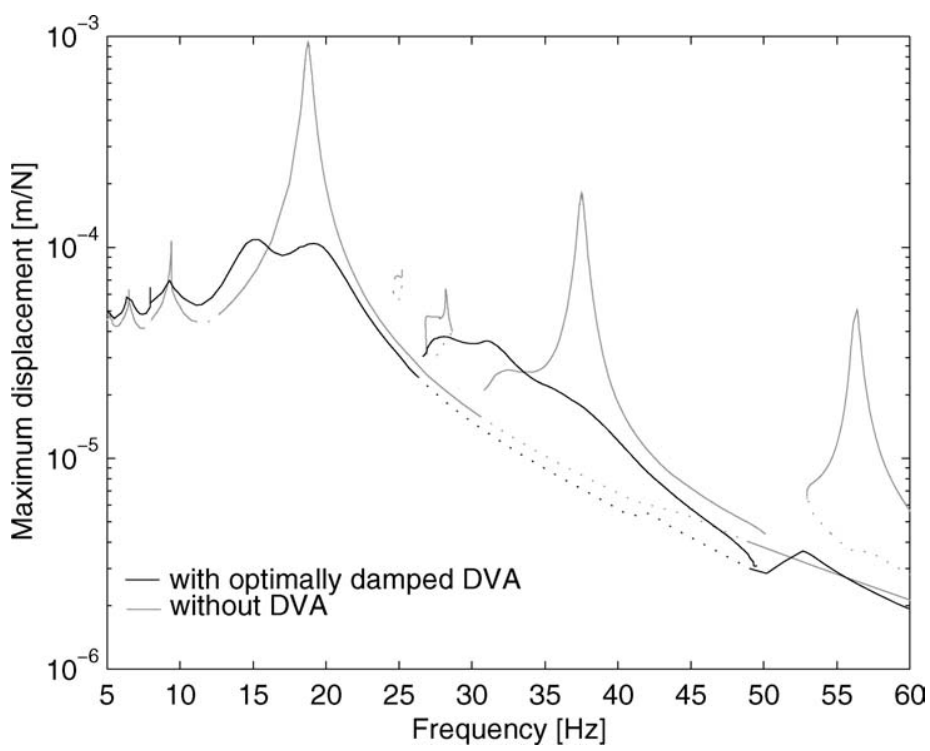

Figure 16. Calculated maximum transversal displacement of the middle of the beam divided by the excitation force amplitude for excitation frequencies in the range $5-60 \mathrm{~Hz}$ using a damped DVA.

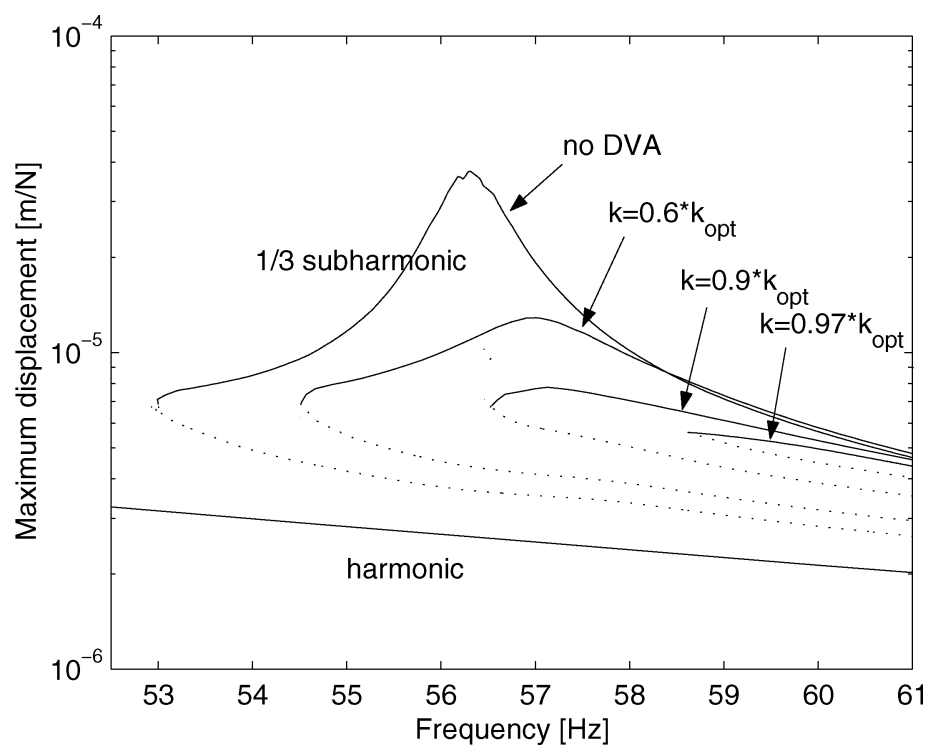

Figure 17. Calculated maximum transversal displacement of the middle of the beam divided by the excitation force amplitude for excitation frequencies in the range 53-61 Hz using several different DVA stiffnesses.

the main beam system. It should be noted that this experimental configuration differs a little bit from the single DOF mass-spring-damper DVA because the damping forces act on a somewhat different position of the main beam than the spring force. Nevertheless, the DVA is modelled as a single DOF mass-spring-damper system in order to keep the number of DOFs small and consequently to limit the computational effort.

By adjusting the orifices of the air dampers and moving the DVA masses, it is tried to tune the damping and stiffness according to (5) and (4), respectively. Unfortunately, it appears to be impossible to obtain 


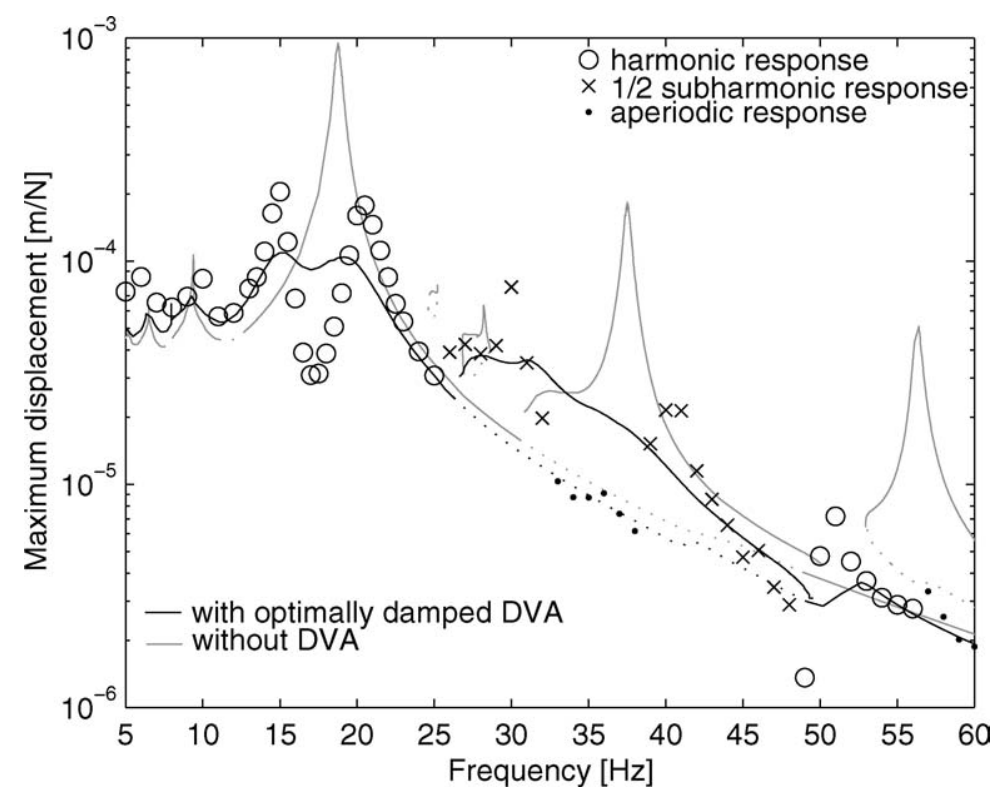

Figure 18. Maximum transversal displacement of the middle of the beam divided by the excitation force amplitude for excitation frequencies in the range $5-60 \mathrm{~Hz}$ using a damped DVA.

a damping value as high as desired, due to the compressibility of the air in the dampers. As a result, the DVA is not optimally damped.

Figure 18 shows the experimentally obtained maximum transversal displacements of the middle of the beam divided by the excitation force amplitude for a range of excitation frequencies using the non-optimally damped DVA (markers). The calculated responses without DVA and using the optimally damped DVA are shown as well (lines). It can be seen that the original harmonic resonance peak is flattened using the non-optimally damped DVA. In addition, many super- and subharmonic resonances which are present in the case of the undamped DVA (see Figure 9) have disappeared.

\section{Conclusions and Recommendations}

In this paper a linear DVA has been applied to a piecewise linear beam system to suppress the first harmonic resonance. This turns out to work very well for this system with a moderate amount of nonlinearity. Both a damped as well as an undamped DVA have been applied. Experiments and simulations have been carried out and compared. The experimental and simulated results show a good resemblance.

The results show that the undamped DVA suppresses the first harmonic resonance of the piecewise linear beam system in a way similar to the linear case. In addition many subharmonic responses appear and also two quasi-periodic $\rightarrow$ locked $\rightarrow$ chaotic sequences have been found. However, no unstable behaviour of the harmonic anti-resonance has been found. Several different DVA masses have been tried, but none results in unstable behaviour of the harmonic anti-resonance. For the undamped linear DVA it can therefore be concluded that it indeed seems possible to suppress the harmonic resonance peak in the piecewise linear beam system. However, it cannot be guaranteed yet that no coexisting solution with high amplitude exists besides the harmonic anti-resonance.

Calculations show that the damped DVA suppresses the harmonic resonance in a way similar to the linear case and also suppresses its corresponding super- and subharmonic resonances. Experiments 
with an optimally damped DVA could not be carried out due to the compressibility of the air in the air dampers. Yet a non-optimally damped DVA does flatten the resonance peaks in the experiments.

Future research should investigate the behaviour of the piecewise linear beam system including the DVA for the case that the one-sided stiffness is applied with a certain amount of pre-stress or backlash. This situation is more comparable to some problems in industrial applications. In addition, it could be investigated whether the approach of the linear DVA also works in the case of a high amount of nonlinearity.

It is also worth trying to suppress the harmonic and subharmonic resonances of the piecewise linear beam using a damped piecewise linear DVA, i.e. a damped DVA with two different stiffness regimes. In this way it might be possible to suppress the resonances of the beam system even better because the time response of the DVA, in opposite phase, could resemble the time response of the beam.

\section{References}

1. Hartog, J. P. den, Mechanical Vibrations, McGraw-Hill, 1956.

2. Hunt, J. B., Dynamic Vibration Absorbers, London: Mechanical Engineering Publications, 1979.

3. Korenev, B. G. and Reznikov, L. M., Dynamic Vibration Absorbers, Wiley, 1993.

4. Shaw, S. W. and Holmes, P. J., 'A periodically forced piecewise linear oscillator', Journal of Sound and Vibration 90(1), 1983, 129-155.

5. Thompson, J. M. T., Bokaian, A. R., and Ghaffari, R., 'Subharmonic resonances and chaotic motions of a bilinear oscillator', Journal of Applied Mathematics 31, 1983, 207-234.

6. Natsiavas, S., 'On the dynamics of oscillators with bi-linear damping and stiffness', International Journal of Non-Linear Mechanics 25(5), 1990, 535-554.

7. Fey, R. H. B., 'Steady-State Behaviour of Reduced Dynamics with Local Nonlinearities', Ph.D. Thesis, Eindhoven University of Technology, The Netherlands, 1992.

8. Vorst, E. L. B. van de, 'Long Term Dynamics and Stabilization of Nonlinear Mechanical Systems', Ph.D. Thesis, Eindhoven University of Technology, The Netherlands, 1996.

9. Pun, D. and Liu, Y. B., 'On the design of the piecewise linear vibration absorber', Nonlinear Dynamics 22, $2000,393-413$.

10. Fey, R. H. B. and van Liempt, F. P. H., 'Sine sweep and steady-state response of simplified solar array models with nonlinear elements', in Proceedings of the International Conference on Structural Dynamics Modelling; Test, Analysis, Correlation and Validation, Vols. 201-210, N. M. M. Maia, J. M. Montalvao e Silva, and A. M. Relogio Ribeiro (eds.), Funchal, Madeira, Portugal, 2002.

11. Rubin, S., 'Improved component-mode representation for structural dynamic analysis', AIAA Journal 13(8), $1975,995-1006$.

12. Newhouse, S., Ruelle, D., and Takens, F. 'Occurrence of strange axiom-a attractors near quasi periodic flow on $T^{\mathrm{m}}, m \leq 3$ ', Communication Mathematical Physics 64, 1978, 35-40.

13. Grebogi, C., E. Ott, and Yorke, J. A., 'Are three-frequency quasiperiodic orbits to be expected in typical nonlinear dynamical systems?', Physical Review Letters 51, 1983, 339-342.

14. Pazo, D., Sanchez, E., and Matias, M. A., 'Transition to high-dimensional chaos through quasiperiodic motion', International Journal of Bifurcation and Chaos 10, 2001, 2683-2688.

15. Wolf, A., Swift, J. B., Swinney, H. L., and Vastano, J. A., 'Determining Lyapunov exponents from a time series', Physica 16D, 1985, 285-317.

16. Hegger, R., H. Kantz, and Schreiber, T., 'Practical implementation of nonlinear time series methods: The TISEAN package', Chaos 9, 1999, 413-435. 